\title{
Surgical Management of Spinal Meningioma
}

\author{
MOHAMED A. HEWEDY, M.D. and MOHAMED MOHAMED, M.D. \\ The Department of Neurosurgery, Faculty of Medicine, Beni-Suef University, Beni-Suef, Egypt
}

\begin{abstract}
Background: Meningioma is a common tumor that accounts for $25-46 \%$ of spinal neoplasms. It is generally benign, and slow growing. Spinal meningiomas occur after the fourth decade of life Mostly, they are located in the intradural compartment, generally respecting the pial layer of the spinal cord. The most frequent site of spinal meningiomasis in the thoracic region Clinical findings variate from mild to significant neurologic dysfunction; the most frequent clinical findings are back pain,sensori-motor deficit and sphincter dysfunction. The goal of surgical treatment must be total resection, if possible and usually not difficult.
\end{abstract}

Objective: This study was made to present the incidence, clinical presentation, localization, techniques, used in the management of spinal meningioma. And to evaluate the functional outcome of surgically treated cases.

Patients and Methods: This is a retrospective study of Sixteen patients with spinal meningiomas who had undergone microsurgical resection were treated between 2012 and 2015 in our department. Clinical presentation, diagnosis, histological examination, microsurgical resection, functional outcome were evaluated, defining potential prognosis factors associated with these lesions.

Results: Tumors site was intradural,extramedullary the most common site was the thoracic region, posterolateral and antero-lateral. Surgical resection was complete in 14 patients $(87.5 \%)$ and incomplete in 2 patients $(12.5 \%)$ At the last follow-up the neurological state was improved or unchanged in 15 patients $(93.75 \%)$ and worse in one patients $(6.25 \%)$.

Conclusion: Magnetic resonance imaging is the best imaging technique for diagnosis. Total tumor resection improved the surgical results of spinal meningiomas.

Key Words: Extramedullary - Intradural - MeningiomaSpinal surgery - Spinal tumors.

\section{Introduction}

MENINGIOMAS involving the spinal cord are relatively rare in comparison to the intracranial compartment accounting approximately $1.2 \%$ of

Correspondence to: Dr. Mohamed A. Hewedy, E-Mail: momashrabia@yahoo.com all meningiomas of the central nervous system $[1,2]$. Mostly, they are located in the intradural compartment, generally respecting the pial layer of the spinal cord. Isolated extradural spinal meningiomas are rare [3]. By the introduction of modern neuroimaging techniques and standard microneurosurgical procedures, these tumours nowadays can be removed with a low morbidity and mortality $[2,4]$. Spinal meningiomas occur after the fourth decade of life, over $70 \%$ of the patients are between the ages of 40 and 70 years with a mean age of 50 years $[1,5]$, thus, the occurrence in younger patients should raise the suspicion of a genetically determined disorder as neurofibromatosis 2 or an association with aggressive histological subtype [6,7] They are slow growing tumours and therefore, they lead to symptoms due to significant spinal cord compression. Local pain is one of the leading symptoms, however, in aconsiderable number of patients diagnosis is confirmed not until neurological deficits or gait disturbances are present $[\mathbf{3 , 8 , 9}]$

\section{Patients and Methods}

Between January 2012 and December 2015 a total of 16 patients with a spinal meningioma underwent micro neurosurgical resection. Exclusion criteria included. (1) Meningioma en plaque or totally calcified tumors, (2) Foramen magnum meningioma as they have intra cranial compartment. (3) Patient with complete hemiplagia, (4) Recurrent cases The female gender was clearly predominant with 14 female patients and 2 male patients (female/male ratio 7:1) All these patients were examined preoperatively including: Age-the mean age was 69 years (range 17-88 years), the mean duration of symptoms was 13,7 months, scoring of motor weakness and sensory deficits, was done. All patients were followed-up clinically and by spinal MRI. The mean follow-up period was 12 months Histological examination of the specimen confirmed a grade I meningioma accord- 
ing to the WHO classification in 14 patients and an atypical meningioma grade II in 2 patients. Contrast enhanced spinal MRI was the diagnostic tool of choice and performed routinely for preoperative evaluation in all patients. To determine the spinal level, size and the dural attachment of the meningioma and its relation to the spinal cord. All meningiomas were operated in the prone position using a microsurgical technique via a midline skin incision extending two levels above and below the extent of the lesion. A monosegmental or multisegmental laminectomy was performed above and below the extent of the tumor removal of the meningioma was performed under standard microsurgical conditions, when necessary, a surgical aspirator (Cooper Ultrasonic Surgical Aspirator) and laser were also applied. In 5 cases intraoperative monitoring of somatosensory evoked potentials (SSEP). Was used the dural attachment was completely resected if the spinal menigioma was located dorsally or dorsolaterally. In these cases, duraplasty was performed with autologeous fascia obtained during the operative approach. In ventrally located tumours the dural attachment was not excised but extensively bipolar cauterized After tumor completely removal and careful hemostasis, the dura was primarily closed in a watertight manner. The grading system according to Simpson (1957) for meningiomas in this area. Therefore, meningiomas of this study resection was defined as "complete" according to intraoperative observations and postoperative MRI corresponding to Simpson's grade I or II.

\section{Results}

There were 14 female and 2 male patients. Age ranged from 17 to 88 years (mean 69 years). The mean follow-up period was 12 months including a complete neurological examination and postoperative MRI studies Tumors site was thoracic, intradural, extramedullary, most common, posterolateral 11 cases, antero-lateral 2 cases, anterior to the spinal cord 1 cases; cervical intradural, extramedullary, postero-lateral 1 cases, anterior to the spinal cord 1 case and no cases were reported in the lumbar region in this study motor deficits were in $81.25 \%$ of the patients. Gait disturbances were observed in $75 \%$. In $37.5 \%$ the patients were unable to walk due to significant neurological deficits and half of the patients (50\%) complained about local pain. Sensory loss in (50\%) Sphincter disturbances were found in 13 patients $(31.25 \%)$. Histopathology revealed the presence of meningiomas WHO grade I lesions: Meningotheliomatous type 11 cases, psammomatous type 1 cases, transi- tional type 1 cases, fibrous type 1 case, microcystic one case and only 2 cases a typical meningioma WHO grade II in 14 case $(87.5 \%)$ the spinal meningioma was removed completely (Simpson's grade I or II) and in 2 cases (12.5\%) incompletely (Simpson's grade III). Partial tumour calcification was observed in two patients (12.5\%) and complete calcification in one cases $(6.25 \%)$. Transient motor deficits were observed in 2 cases anteriorly placed tumors one thoracic and one cervical A postoperative DVT occurred in two cases, a cerebrospinal fluid fistula in 2 cases and a prolonged wound healing in one case. None of these patients required surgical repair and all recovered completely with conservative treatment we had recurrence in one patient which had a complete tumour resection initially his histological examination was WHO grade I the patient with recurrent tumour underwent a second operation. The tumour was resected completely and the new histopathology was semimalignant meningioma. Considering the functional outcome $63.5 \%$ who were able to walk indecently became $81.25 \%$.

\section{Case presentation:}

Thirty five year old, housewife, female patient.

\section{Complaints:}

- Back pain for 9 months.

- Bilateral lower limb heaviness for 1 months.

\section{Examination:}

- Bilateral lower limb weakness Grade IV.

- Mild hypertonia in both lower limb.

- Mild hyperreflexia in both lower limb.

- Sensory level at the umbilicus.

- Continent.

- No pathological reflexes.

\section{Imaging:}

- MRI dorsal spine was done showed: D11,12 well-circumscribed, broad-based dural attachment mass, homogeneous enhancement compressing the spinal cord.

- In T1 isointense to slightly hypointense.

- In T2 isointense to slightly hyperintense.

\section{Operative findings:}

- Excision was performed through posterior approach.

- Midline back skin incision.

- Laminectomy of D11, 12.

- Opening of the dura matter. 
- Total surgical excision of the Intradural extramedullary mass. Extracted tumor showing a well encapsulated mass measuring $1.6 \times 1$ $\mathrm{x} 0.8 \mathrm{~cm}$.

- Closure of the dura and wound in layers.
Postoperative: The patient has excellent result pain and weakness improved.

Post operative MRI: Was performed showing mass removal at D11,12 level.

Pathology: Transitional meningioma WHO G 1 .

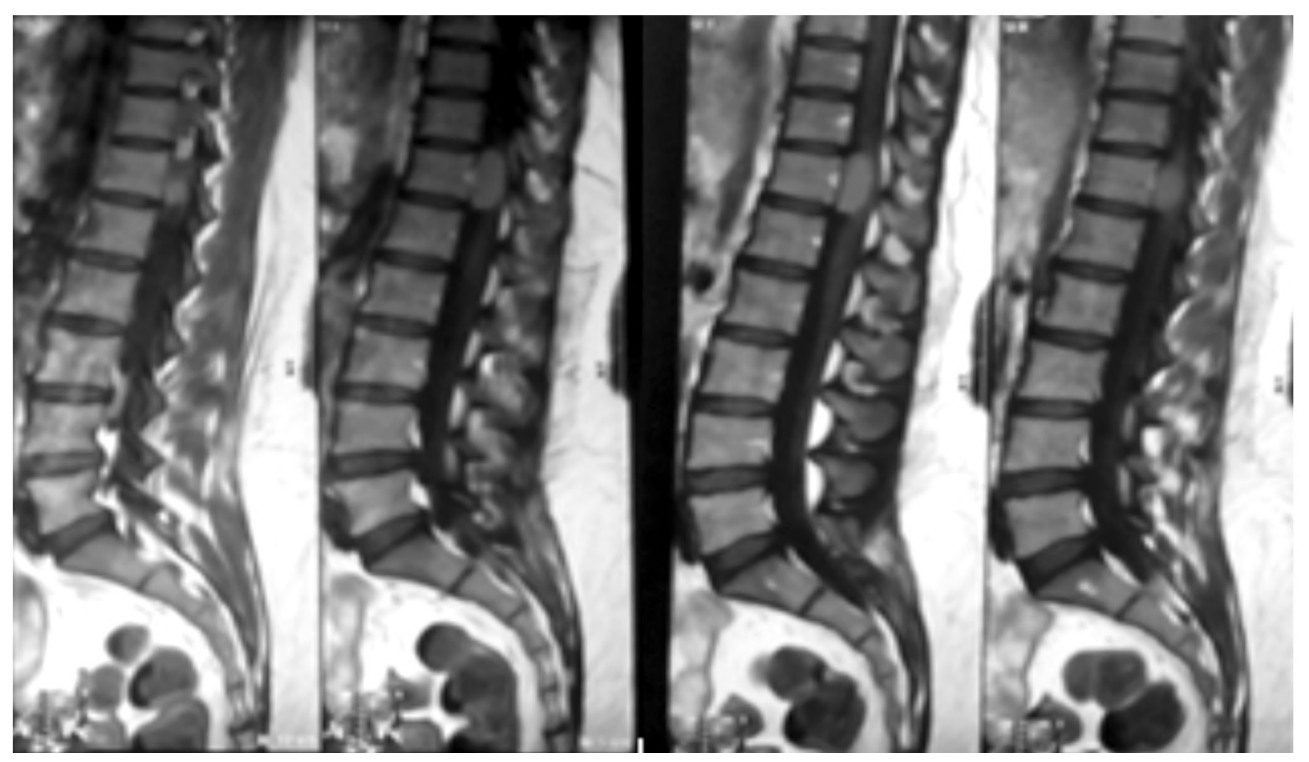

Fig. (1): Preoperative sagittal T1-weighted MRI with contrast showing homogeneous enhancement D11, 12 lesion.

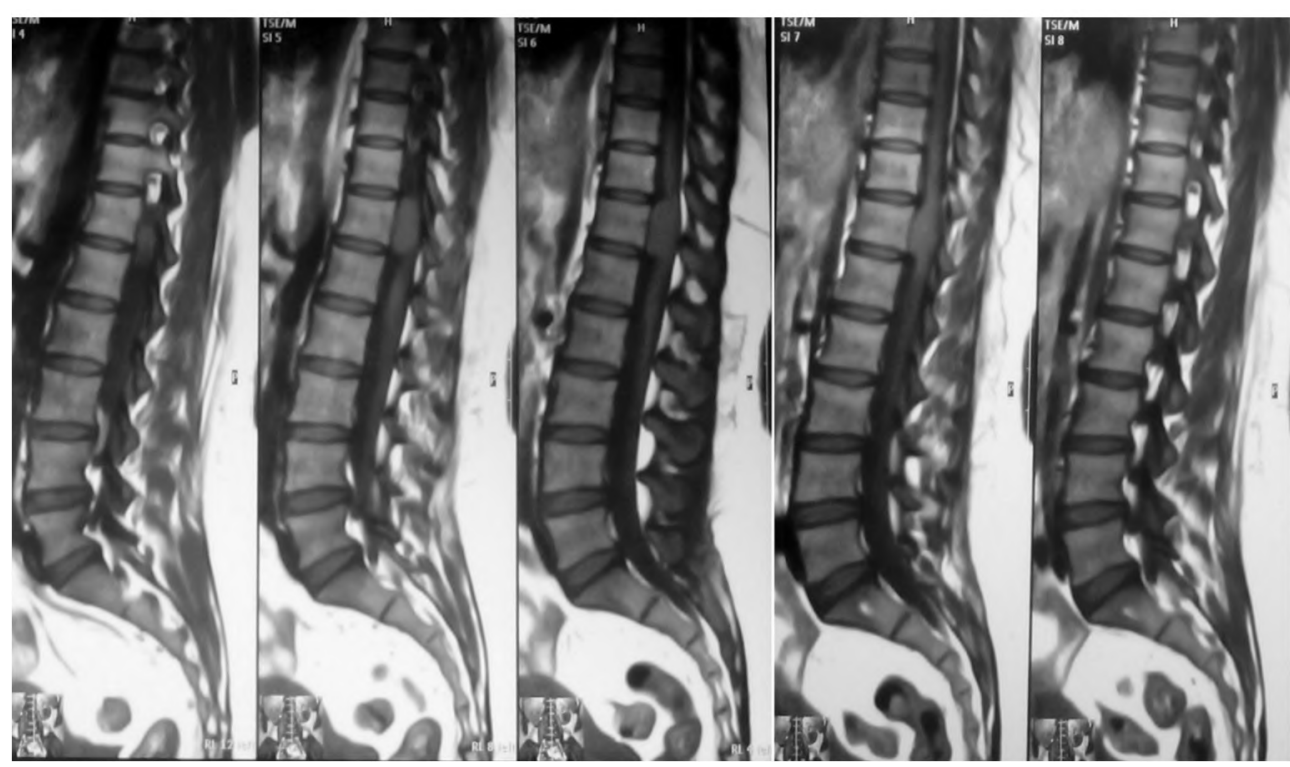

Fig. (2): Preoperative sagittal T1-weighted MRI showing slightly hypointense D11,12 lesion. 


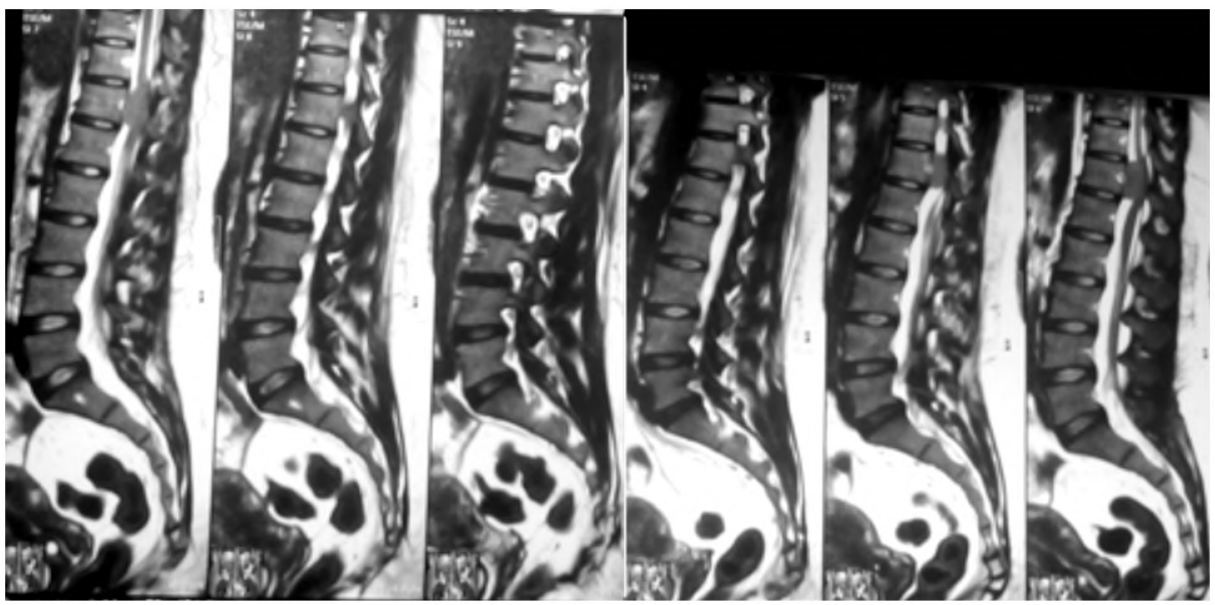

Fig. (3): Preoperative sagittal T2-weighted MRI slightly hyperintense D11, 12 lesion.

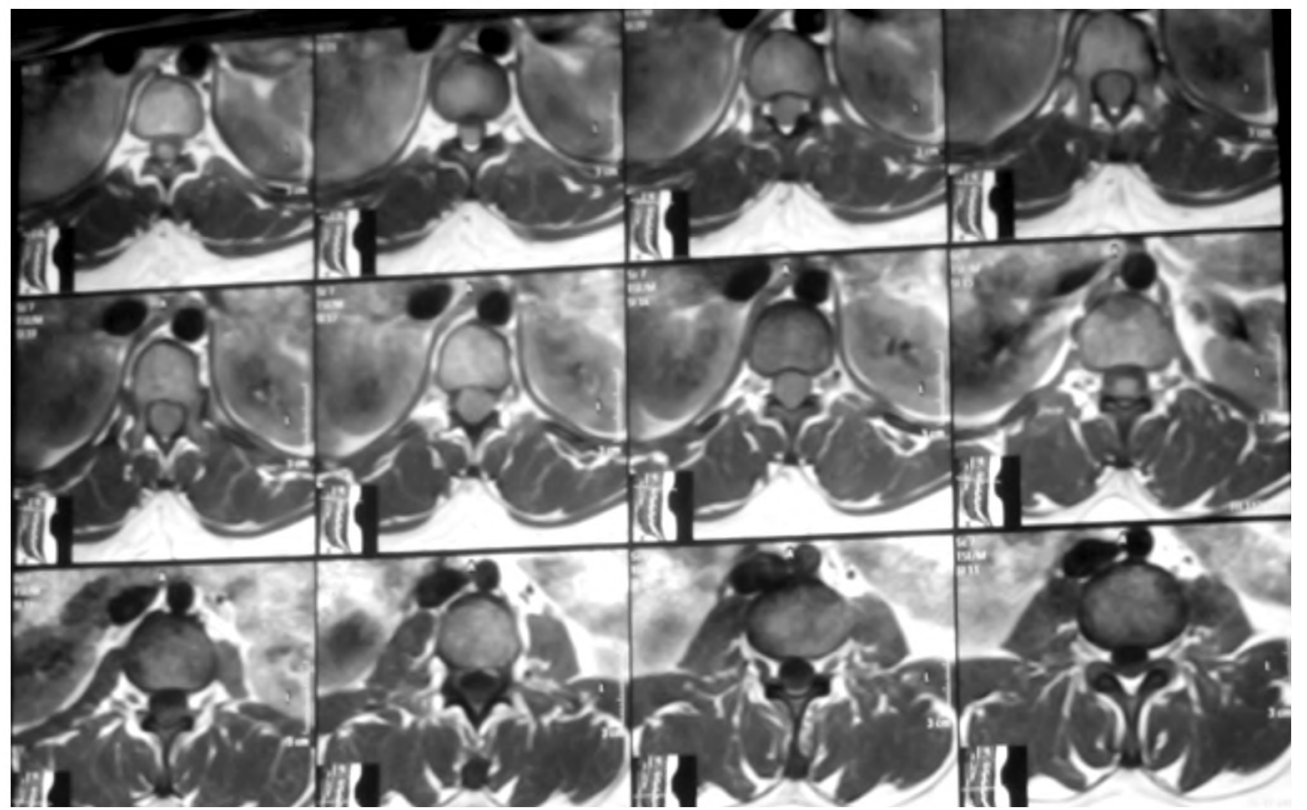

Fig. (4): Preoperativeaxial T2weighted MRI slightly hyperintense D11, 12 lesion compressing the cord.

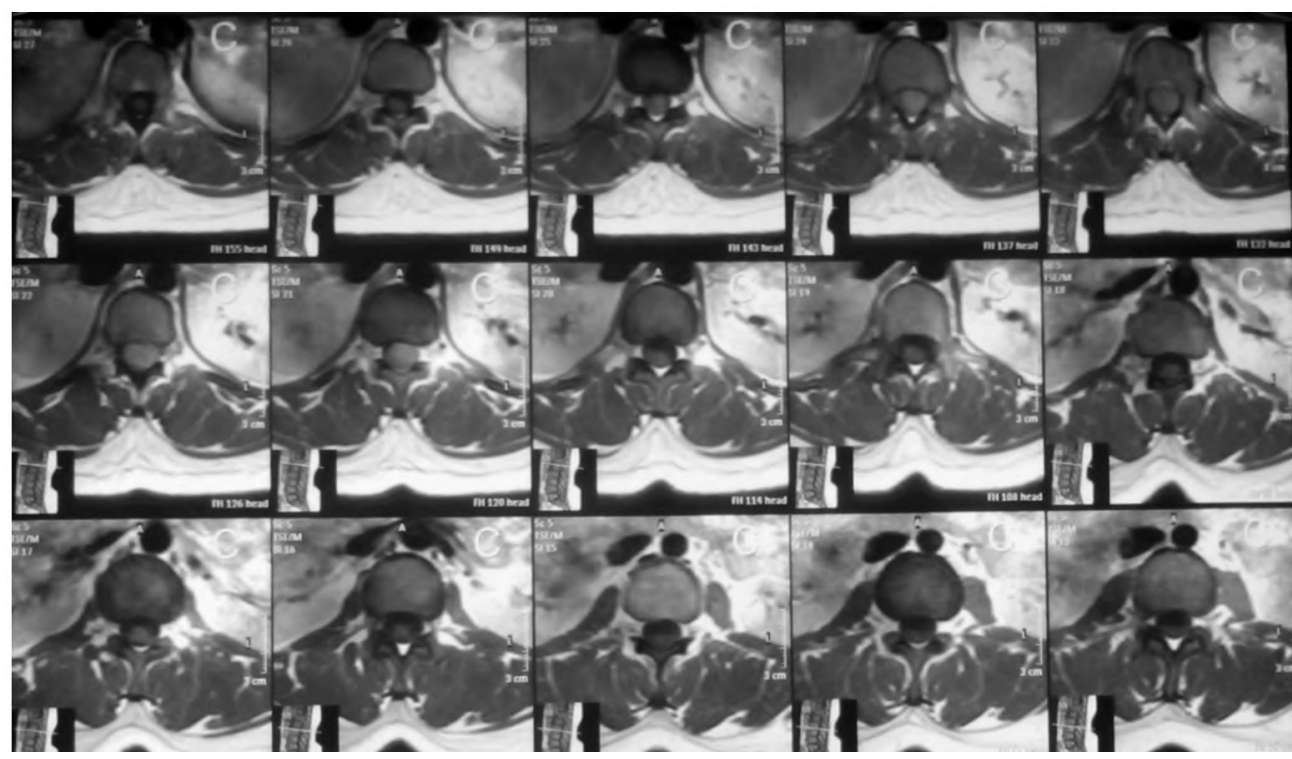

Fig. (5): Preoperativeaxial T1weighted MRI with contrastshowing homogeneous enhancement D11, 12 lesion. 


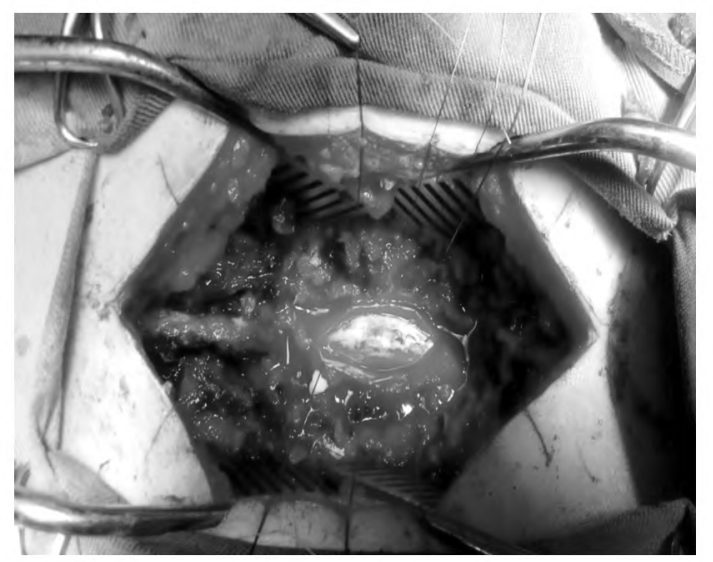

Fig. (6): Intra-operative findings of intradural extramedullary mass excision.

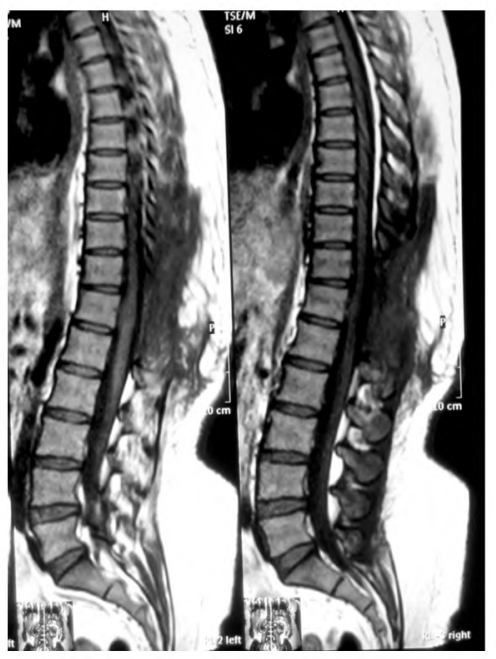

Fig. (8): Post-operative sagittal T1W MRI showing mass removal at D11-D12 level.

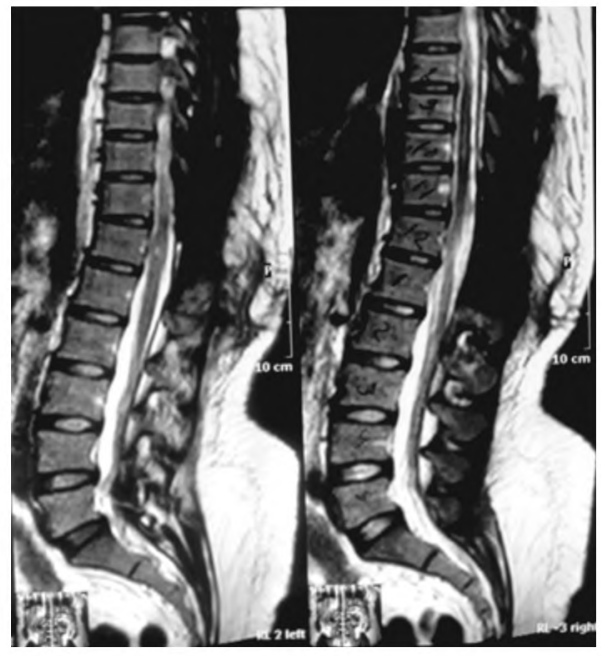

Fig. (7): Post-operative T2W MRI showing mass removal at D 11-D 12 level.

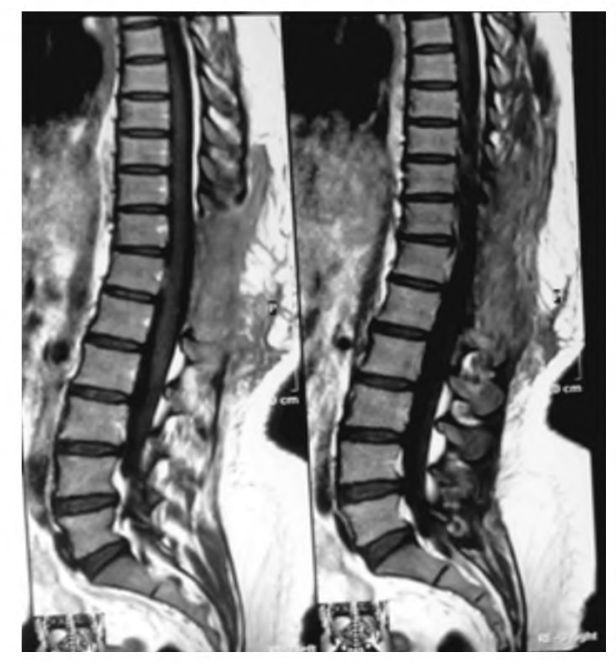

Fig. (9): Post-operative sagittal T1W MRI with contrastshowing total mass removal at D11-D12 level.

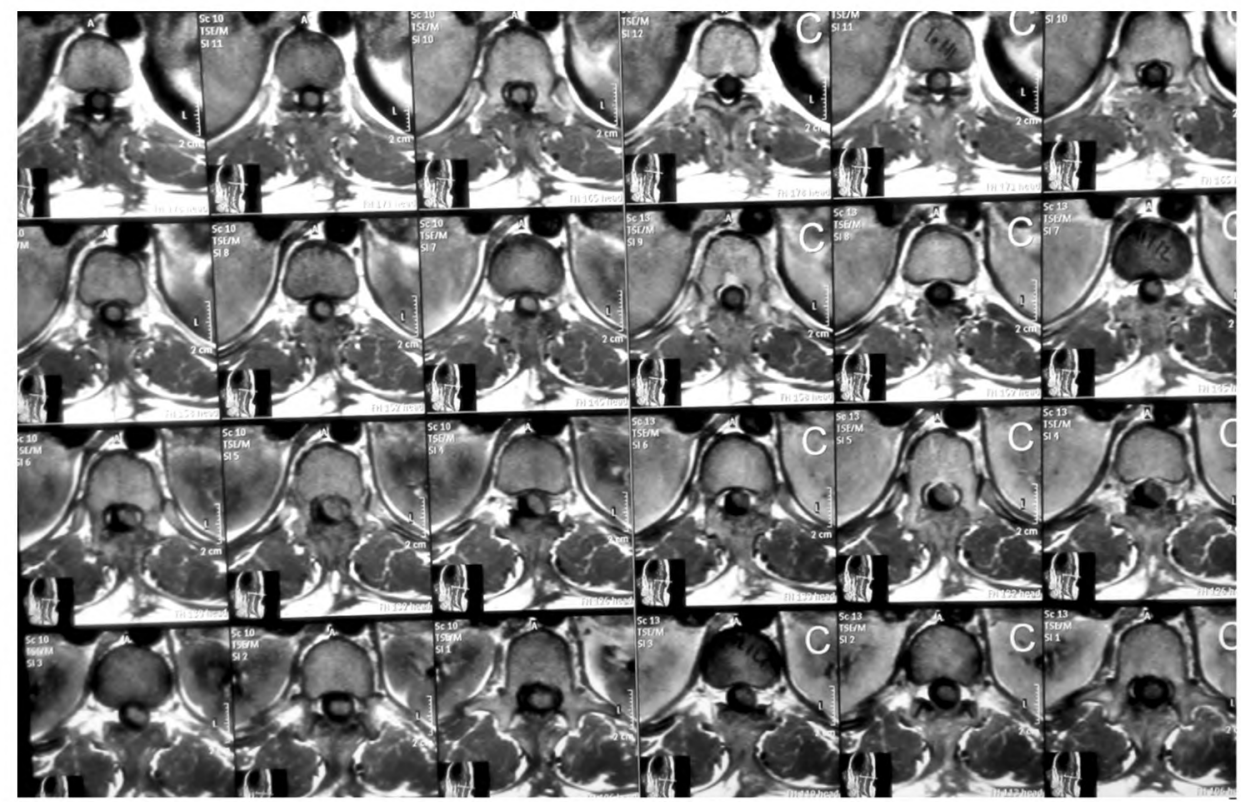

Fig. (10): Post-operative axial T1W with and without contrast MRI with contrastshowing total mass removal at D11-D12 level. 


\section{Discussion}

Meningiomas are benign tumours mostly located in the intracranial compartment. Spinal meningiomas are rare and account about $1.2 \%$ of all meningiomas and $25 \%$ of all spinal cord tumours [8]. The first case of a successful removal was accomplished by Victor Horsley more than a century ago $[10,11]$. The primary goal of surgery is to achieve complete tumour removal and to avoid additional neurological damage. In the era before the introduction of the microscope in neurosurgery, good results were reported although some postoperative transient neurological deterioration was observed by some authors $[\mathbf{7 , 1 2 , 1 3 ]}$. In the last decades, safety of neurosurgical procedures increased due to technical developments for tumour resection and the routine use of neurophysiological intraoperative monitoring [14-16]. There is a female predominance in the adult population: female to male ratio is $2: 1$ in intracranial meningiomas and 9:1 for spinal meningiomas, no sex predilection in children [17-20]. In my present series, thefemale/ male ratio was 7: 1 . Female predominance could be explained by hormonal factorsAlthough the theory about the effect of hormones on meningioma has been controversial, hormonal studies have shown the existence of progesterone and estrogen receptors frequently found on histological examination, as well as the reports of an association between meningioma and breast cancer.

The presumed site of origin of spinal meningiomas from arachnoidal cap cells located in the leptomeninges at the spinal nerve root exit zones, adiacent to them denticulate ligaments or entry zones of arteries in the spinal canal; explaining why these tumors frequently arise in a lateral location to the spinal cord [21,22]. The most common topography is the thoracic spine $80 \%$, (laterally $45-71 \%$, postero-laterally $10-31 \%$ or anterolaterally to the spinal cord $15-27 \%$ in our study the results were $87 \%$, in the thoracic region and their distribution was (laterally $68.75 \%$, posterolaterally $12.5 \%$ or antero-laterally to the spinal cord $6.25 \%$ ) in the cervical it is present in $15 \%$ of cases and tends to be more anterior in our study it was $12.5 \%$ of cases spinal meningioma is very rare in lumbar spine $1-2 \%$ our study did not include any lumbar cases. Unspecific symptoms as local pain are often misinterpreted, until diagnosis is confirmed by neuroimaging procedures. At the time of diagnosis, however, a considerable number of patients were not able to walk independently. Delay of diagnosis as the result of failure to consider a slow growing spinal tumour responsible for longstanding back pain or neurological deficits was already observed by Pena et al., [23]. In our series the rate of patients unable to walk was $37.5 \%$. This is in accordance with the literature. Klekamp et Samii reported that $59 \%$ demonstrated gait ataxia as predominant neurological symptom on admission, and a total of 31 out of 117 patients (26.5\%) were unable to walk [18]. In other series, the rate of patients unable to walk independently ranges between 21 and 53\% [4-6,8,10,15,18]. In our study, the rate of complete resection of spinal meningiomas was $87.5 \%$. This rate is in accordance with the literature, where the rates of complete tumour removal are reported to be between 82 and $98 \%$ $[4-8,13,15,18]$. Complete resection according to Simpsons grade II was performed in our study group. The rate of resection of the dural attachment is reported to be between 14 and $58 \%$ [8,13,15,18] This is the result of the posterior operative approach in almost all cases and the difficulty of dural reconstruction ventral to the spinal cord. Tumour resection and following bipolar coagulation is generally considered to be adequate and effective. Concerning the functional results of surgery. In our study the outcome was improved or unchanged in $93.7 \%$ at the time of last follow-up. Before surgery only $63.5 \%$ of our patients were able to walk independently, after surgery significant improvement was observed and this rate increases up to $81.25 \%$. Similar results were reported by others. In Klekamp. Samii's series, 31 out of 117 patients were unable to walk preoperatively. Of these, $29 \%$ could walk again before discharge and 57\% within 3 months of rehabilitation [18]. In earlier series, others observed that the immediate postoperative course was characterized by a moreor-less pronounced transient neurological deterioration [18]. In our study we faced it in 2 cases After the introduction of the operative microscope and microneurosurgical procedures, the percentage markedly declined . Excellent or good results range between 79 and $98 \%[\mathbf{4 , 7 , 8 , 1 3 , 1 5 , 1 8 ] . ~ P o t e n t i a l ~ r i s k ~}$ for permanent neurological deterioration. In our study, the existence of tumour calcification bears an increased risk for poor neurological outcome [8]. The evidence of calcification makes surgical removal difficult and increases the risk for neurological damage study Morandi et al., evaluated 30 patients over 70 years and reported improved func tional outcome in all cases.and thus denying the relation between age and outcome [5-22]. In our study we had recurrence in one case $6.25 \%$. The recurrence rate for spinal meningiomas is generally low ranging between 0 and $13 \%$ although the grade of tumour resection was Simpson's grade II in the majority of in the presented series [4,8-10,18]. Mirimanoff et al., evaluated the recurrence rate of 
meningiomas and their progression after neurosurgical resection. They observed no tumour recurrence within the first 5 years, but a rate of $13 \%$ at the 10 years follow-up [9]. In the literature, there seems to be no doubt that there is no correlation between the extension of dural resection and the risk for tumour recurrence. Some authors rather observed a higher recurrence rate in patients with radical tumour resection compared to patients, where the dural attachment was coagulated only $[8, \mathbf{1 8}]$. Reoperation with total tumour resection is generally possible, but remains a surgical challenge.

Some centers advocate adjuvant radiotherapy for recurrent tumours, but there is still a lack of evidence that radiotherapy reduces the risk of tumour regrowth $[\mathbf{2 4 , 9 , 1 3 ]}$. Thus, adjuvant radiation treatment should be preserved for malignant spinal meningiomas only.

\section{Conclusion:}

Despite the retrospective character of this study and its limited cases we can conclude that resection of spinal meningiomas is a safe and most effective procedure. There might be a higher surgical risk for calcified tumours, incomplete resection. According to Simpsons grade II is the result of the posterior operative approach in almost all cases and the difficulty of dural reconstruction ventral to the spinal cord. Tumour resection and following bipolar coagulation is generally considered to be adequate and effective. And does not increace the recurrence rate.

\section{References}

1- GEZEN S., KAHRAN S., CANAKCI Z. and BEDUK A.: Review of 36 cases of spinal cord meningioma. Spine, 25: 727-731, 2000.

2- ALBANESE V. and PLATAIA N.: Spinal intradural extramedullary tumors. Personal experience. J. Neurosurg. Sci., 46: 18-24, 2002.

3- COHEN A.A., ZIKEL O.M. and KOCH C.A.: Spinal meningiomas in patients younger than 50 years of age: a 21-year experience, J. Neurosurg. (Spine), 98: 258-263, 2003.

4- GOTTFRIED O.N.: Spinal meningiomas: Surgical management and outcome, Neurosurg. Focus., 14 (6): e2, 2003.

5- MORANDI X. and HAEGELEN C.: Results in the operative treatment of elderly patients with spinal meningiomas. Spine, 29: 2191-2194, 2004.

6- HAEGELEN C.: Results of spinal meningioma surgery in patients with severe preoperative neurological deficits. Eur. Spine, 14: 440-444, 2005.

7- CAVANAUGH D.A.: Intraspinal meningioma in a 10- year-old: Should age determine the aggressiveness of intervention?, Surg. Neurol., 69: 130-134, 2008.

8- RIAD H.S. and KNAFO S.: Spinal meningiomas: Surgical outcome and literature review, Neurochirurgie, 59: 3034, 2013.

9- ACHARI G.: Extradural meningioma en-plaque of the cervical cord, Neurol. Res., 22: 551-553, 2000.

10- CAROLI E., ACQUI M. and ROPERTO R.: Spinal enplaque meningiomas: A comtemprary experience. Neurosurgery, 55: 1275-1279, 2004.

11- SARACENI C. and HARROP J.S.: Spinal meningioma: chronicles of contemporary neurosurgical diagnosis and management, Clin. Neurol. Neurosurg., 111: 221-226, 2009.

12- SANDALCIOGLU I.E.: Spinal meningiomas: Critical review of 131 surgically treated patients. Eur. Spine. J., 17: 1035-1041, 2008.

13- GAMACHE F., WANG J., DECK M. and HEISE C.: Unusual appearance of an en plaque meningioma of the cervical spinal canal. A case report and literature review, Spine, 26 (5): E87-E89, 2001

14- SILVA J.A. and HOLANDA M.M.: Multiple meningiomas within the spinal canal: Case report with 23 tumors, Arq. Neuropsiquiatr., 63: 166-170, 2005.

15- KESKIN F. and KARATAS Y.: Case of Upper Thoracic Intradural-Extramedullary Multiple Meningiomas, Neurosurg. Q., 23: 224-225, 2013.

16- PEKER S.: Spinal meningiomas: Evaluation of 41 patients. J. Neurosurg. Sci. 49: 7-11, 2005.

17- COOPER P.R., WIENECKE R.J. and WHITE B.J.: Spinal Meningiomas, in Batjer H.H., Loftus Ch.M., Textbook of Neurological Surgery, Lippincott Williams \& Wilkins, II, 1857-1864, 2003.

18- KLEKAMP J. and SAMII M .: Surgical results for spinal meningiomas. Springer, 4.5.1: 248-260, 2007.

19- MIRIMANOFF R.O., DOSORETZ de LINGGOOD R.M., OJEMANN R.G. and MARTUZA R.L.: Meningioma: analysis of recurrence and progression following neurosurgical resection. J. Neurosurg., 62: 18-24, 1985.

20- MESSORI A., RYCHLICKI F. and SAVOLINI U.: Spinal epidural en-plaque meningioma with an unusual pattern of calcification in 14-year-old girl: Case report and review of the literature, Neuroradiology, 44: 256-260, 2002.

21- SCHALLER B.: Meningioma: Relationship between histological subtypes and surgical outcome? J. Neurooncol., 75 (2): 157-161, 2005.

22- SACKO.: Spinal meningioma surgery in elderly patients with paraplegia or severe paraparesis: A multicenter study. Neurosurgery, 64: 503-509, 2009.

23- PENA M., GALASKO C.S. and BARRIE J.L.: Delay in diagnosis of intradural spinal tumors. Spine, 17: 11101116, 1992.

24- BRUNA J.: Ki-67 proliferative index predicts clinical outcome in patients with atypical or anaplastic meningioma. Neuropathology, 27: 114-120, 2007. 


\section{التدخل الجراحى للورم السحائى فى العمود الفقرى}

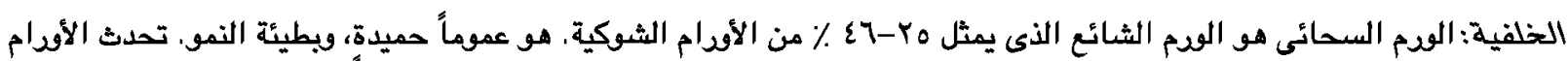

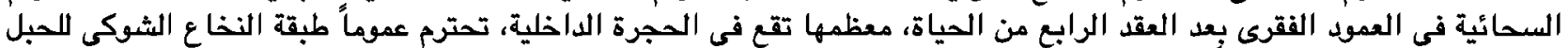

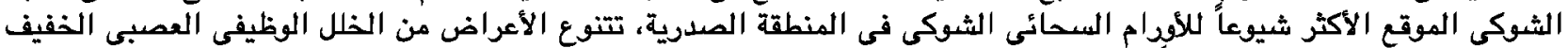

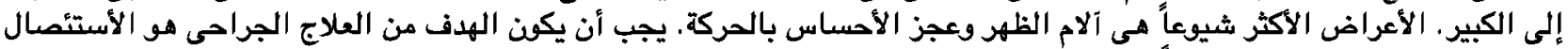
الكلى، إن أمكن، وعادة ليس صعباً.

الهدف: تم إجراء هذه الدراسة لعرض الإصابة إنهابة والأماكن، التقنيات، المستخدمة فى علاج قدم سحايا النخاع الشوكى وتقييم النتائج الوظيفية للحالات المعالجة جراحياً.

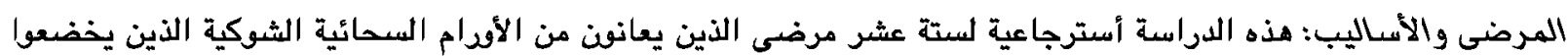

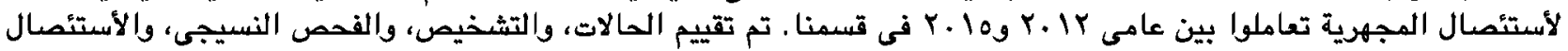
الجراحى المجهرية، والنتائج الوظيفية، وتحديد عوامل التشخيص والثى المحتملة المرتبطة بهذه الأورام.

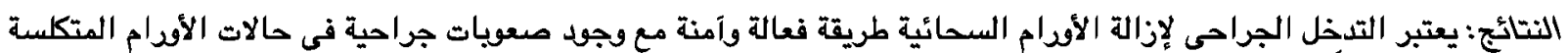

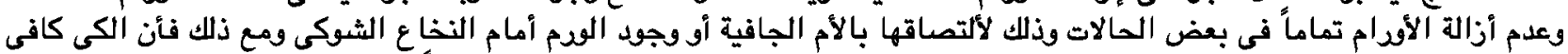

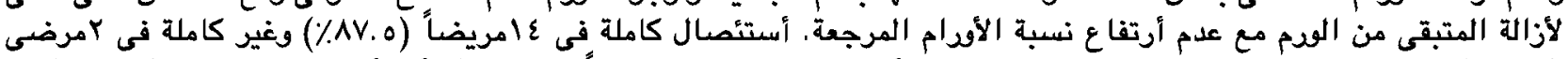

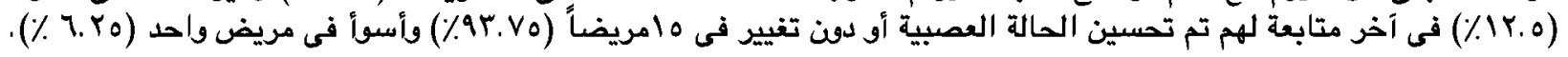

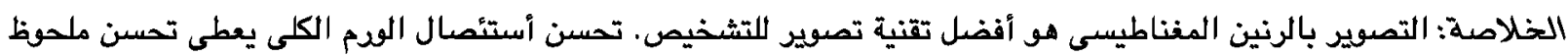
فى النتائج الجراحية لأورام سحائية العمود الفقرى. 